\title{
Dynamic Alterations in the Cutaneous Mechanoreceptive Fields of Dorsal Horn Neurons in the Rat Spinal Cord
}

\author{
C. J. Woolf and A. E. King ${ }^{a}$ \\ Department of Anatomy and Developmental Biology, University College London, London WC1E 6BT, England
}

The effect of the application to the skin of the chemical irritant mustard oil on the size and responsiveness of the cutaneous mechanoreceptive fields of 32 lumbar dorsal horn neurons has been examined in the adult decerebrate, spinal rat. Mustard oil placed on a small region of skin outside the mechanoreceptive firing zone produced a brief (185 \pm 35 sec, SEM) discharge of action potentials in 17 neurons and, in 23 cells, a prolonged increase of the response to a standard low- or high-intensity mechanical stimulus applied to the firing zone of the receptive field. This increase was shown, in 6 intracellularly recorded cells, to be due to a significantly increased depolarization in response to the stimuli. An expansion of the mechanoreceptive firing zones that peaked at $26 \pm 3.7$ min was seen in 21 cells. While 6 of 8 nociceptivespecific neurons and 11 of 18 multireceptive neurons showed such an expansion, it did not occur in the 6 cells with lowthreshold-only receptive fields. The expansion of the firing zones in 4 intracellularly recorded cells was found to be due to an increased amplitude of the EPSPs evoked by stimuli applied to what had initially been low probability firing fringes (Woolf and King, 1989) outside the firing zones, so that subthreshold responses became suprathreshold after application of the mustard oil. In 4 of 8 nociceptive-specific cells, the mechanical threshold in the firing zone became reduced to innocuous levels after application of the mustard oil. The demonstration of the capacity of a relatively brief afferent barrage of chemosensitive nociceptors to produce an increase in the spatial extent of the cutaneous receptive fields of dorsal horn neurons, amplify their responsiveness, and reduce their thresholds has implications both for the pathogenesis of postinjury pain hypersensitivity phenomena and for receptive field plasticity in the somatosensory system.

The spatial extent and responsiveness of the cutaneous receptive fields of dorsal horn neurons are not fixed or immutable. Alterations in receptive fields have been observed in 3 circumstances: in the absence of any peripheral stimuli, following deafferentation, and following tissue-damaging peripheral stimuli. Spontaneous expansions and retractions of receptive fields have been observed in a small number of cells, particularly cells in lamina 2 of the dorsal horn (Hentall, 1977; Dubuisson et al.,

\footnotetext{
Received Jan. 22, 1990; revised Mar. 28, 1990; accepted Mar. 29, 1990.

We thank the MRC and the Wellcome Trust for financial support.

Correspondence should be addressed to Dr. C. J. Woolf at the above address.

a Present address: Department of Physiology, University of Leeds, Leeds LS2 9JT, UK.

Copyright (C) 1990 Society for Neuroscience $0270-6474 / 90 / 082717-10 \$ 03.00 / 0$
}

1979; Woolf and Fitzgerald, 1983) and in dorsal column postsynaptic cells (Brown and Fyffe, 1981; Brown et al., 1983). Deafferentation, either by dorsal root or peripheral nerve section, produces an immediate reduction in the receptive fields of those neurons whose receptive fields fall within the innervation fields of the injured afferents. However, over a period of days, some of these cells begin to respond to novel inputs from distant areas of skin (Devor and Wall, 1981; Hylden et al., 1987; Markus and Pomeranz, 1987). It has been suggested that these new inputs involve either a structural reorganization of synapses on the dorsal horn cells or the unmasking of previously ineffective synapses (Wall, 1977).

Activity-dependent changes in receptive field properties were first shown by studying the capacity of peripheral tissue injury or brief high-threshold afferent inputs to alter the cutaneous receptive fields of flexor motoneurons (Woolf, 1983; Woolf and McMahon, 1985; Woolf and Wall, 1986). Comparable changes have since been shown to occur in dorsal horn neurons, as well. For example, electrical stimulation of small caliber muscle afferents for $20 \mathrm{sec}$ at $1 \mathrm{~Hz}$ produces both an increase in the size of the receptive fields of dorsal horn neurons and a reduction in their threshold that lasts for tens of minutes (Cook et al., 1987). Similar changes have been shown to occur following unilateral experimental inflammation (Hylden et al., 1989), the injection of irritant chemicals into joints (Schaible et al., 1987) or muscle (Hoheisel and Mense, 1989), or the use of noxious thermal stimuli (McMahon and Wall, 1984; Ferrington et al., 1987). These changes in the spatial extent and responsiveness of receptive fields parallel the postinjury pain hypersensitivity phenomenon that is seen both in man (Raja et al., 1988) and in animals (Woolf, 1984).

The cutaneous excitatory receptive fields of dorsal horn neurons can be divided, by intracellular analysis, into firing zones and low-probability firing fringes (LPFFs; Woolf and King, 1989). The firing zone constitutes that skin area where a stimulus produces a discharge of action potentials (Brown and Fyffe, 1981). The LPFF represents that area of skin where the action potential discharge to a stimulus cannot be differentiated from the background discharge, but stimulus-evoked EPSPs are present. Therefore, this LPFF is similar to the subliminal fringe of the rcceptive ficld (Hongo and Koikc, 1975; Brown et al., 1987). The subthreshold input to the cell represents a reservoir of potential responsiveness that could contribute to dynamic receptive field alterations if either the excitability of the dorsal horn neuron or its synaptic efficacy were increased.

We have examined, using extra- and intracellular recordings from dorsal horn neurons, the receptive field plasticity that occurs following the application to the skin of the chemical irritant mustard oil. Mustard oil produces an intense burning sensation 


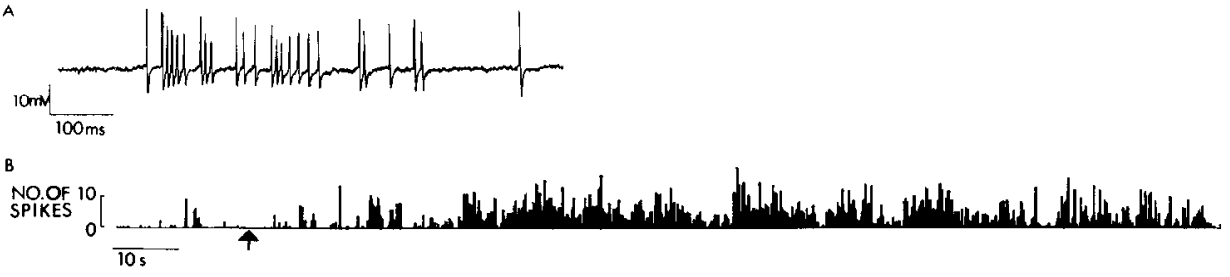

Figure 1. A, Extracellular recording of a deep dorsal horn neuron. $B$, A ratemeter record of the response of the cell to the cutaneous application of mustard oil. Bin width, $100 \mathrm{msec}$. $C$, Changes in the cutaneous receptive field of the cell following mustard oil. The number under each drawing is the time in min following the application of the mustard oil. The site of application of the mustard oil is indicated in the pre-mustard oil drawing.
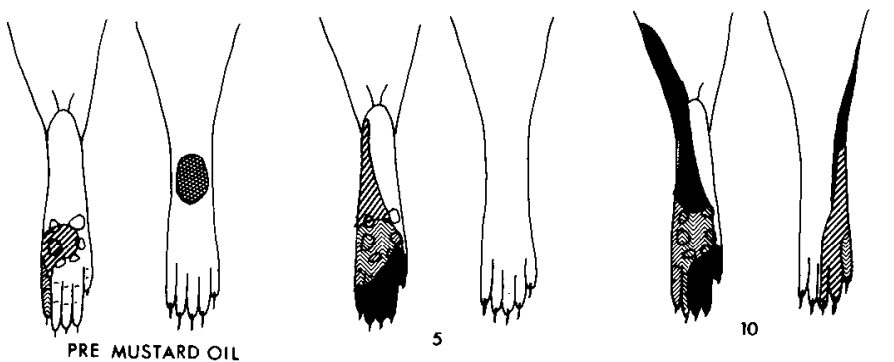

BRUSH / TOUCH "YI/ PINCH BRUSH / TOUCH / PINCH
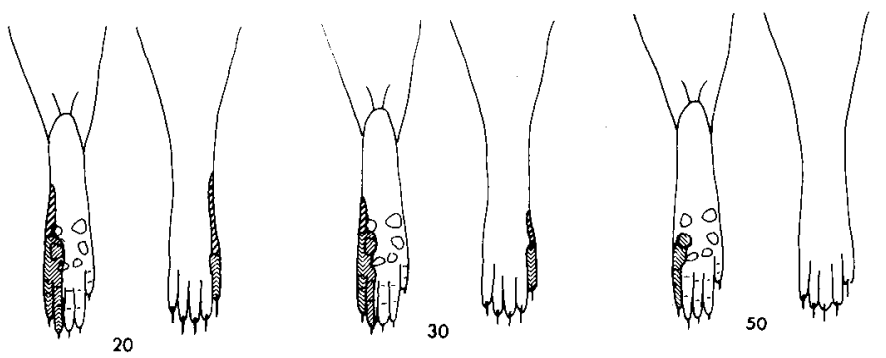

when applied to abraded skin in man and a prolonged facilitation of the flexion reflex when topically applied to rat skin (Woolf, 1984; Woolf and Wall, 1986). The sensory and motor consequences of this irritant considerably outlast the duration of the afferent barrage it generates, which only lasts a few minutes (Woolf and Wall, 1986). Because mustard oil predominantly, if not exclusively, activates $\mathrm{C}$-afferents, it provides a convenient way of studying the dorsal horn changes that follow a brief noxious stimulus-induced $\mathrm{C}$-afferent input. A short report of some of the data has been presented previously (Woolf and King, 1988).

\section{Materials and Methods}

Experiments were performed on 32 acutely decerebrated and spinalized adult rats (210-320 gm). Under ether anesthesia, a carotid artery and the trachea were cannulated. Anesthesia was then maintained with small intermittent doses $(0.1 \mathrm{ml}$, i.a.) of the short-acting anesthetic Althesin (alfaxalone/alphadalone, Glaxo). Decerebration was performed by aspirating all the cranial contents rostral to the mesencephalon, following which the anesthetic was discontinued. The animals were then paralyzed with Flaxedil (gallamine) and artifically ventilated. Rectal temperature, expired partial pressure $\mathrm{CO}_{2}$, heart rate, and $\mathrm{ECG}$ were monitored and maintained within physiological limits.

Spinalization was performed at T8-10 via a small laminectomy, and the lumbar spinal cord (L2-L5) was exposed by a separate laminectomy. The vertebral column was stabilized by vertebral and hip clamps. A curved metal foot was slipped under the spinal cord at the L4 and L5 segments and gently lifted about $1 \mathrm{~mm}$ from the vertebral canal before being fixed in position and surrounded with $3 \%$ agar in saline as described previously (Woolf and King, 1987). The dorsal surface of the cord was covered with mineral oil.

Extracellular recordings were made using glass microelectrodes filled with $3 \mathrm{M}$ potassium acetate (15-35 MR). Only single-unit recordings where the amplitude of the spike exceeded $5 \mathrm{mV}$ were used (Fig. 1A). Using these fine electrodes, by moving the electrode with a microdrive to an optimal position close to a neuron, it was possible to record a

single spike without any contaminating other spike discharge (Fig. 1A). If the spike amplitude fell below $5 \mathrm{mV}$, the experiment was discontinued. Before commencing the experimental manipulation (topical application of mustard oil; see below), a cell was recorded for at least $30 \mathrm{~min}$ to ensure the stability of the recording situation and to define, on repeated occasions, the spatial extent and responsiveness of the receptive field.

Intracellular recordings were made using potassium acetate $(3 \mathrm{M})$ electrodes with impedances of 40-100 M . A search for cells with a microdrive was made at depths of 300-750 $\mu \mathrm{m}$ from the surface of the dorsal horn. No attempt was made to extracellularly study the receptive fields of cells whose spontaneous spike discharges could be seen during the tracking procedure, and, in most cases, the first indication of a cell was a sudden potential shift. Once a cell was impaled that responded to a direct depolarizing pulse $(0.5 \mathrm{nA}$ for $20 \mathrm{msec})$ with action potentials, a search was made for a cutaneous mechanosensitive receptive field. Those cells that showed a steady depolarization following impalement were discarded, as were those where either the action potential amplitude was $<55 \mathrm{mV}$ or there was no overshoot. Input resistances were measured from the steady depolarization or hyperpolarization resulting from steps of current passed through the electrode.

Receptive fields for both the extra- and intracellular recordings were tested using hand-held calibrated nylon filaments (von Frey hairs), blunt probes, camel hair brushes, serrated forceps, and calibrated pinchers applied to the skin of the hindpaw, ankle, calf, and thigh. The data was stored on one channel of an FM tape recorder with a timing signal to indicate the application of stimuli to the skin on another channel. The spike discharge was displayed on chart recordings by counting the number of spikes over 50 -msec bins.

The approach used to find the firing zone of the receptive fields of the intracellularly recorded cells was identical to that previously described in detail (Woolf and King, 1989). Subthreshold responses were analyzed off-line, and, because there was no way of knowing during the experiment which skin areas evoked such responses, a standard sequence of stimuli was applied, including brushing the entire hairy skin of the hindlimb, applying a low force von Frey hair $(2.4 \mathrm{gm})$ to different parts of the glabrous skin (each of the toes, pads, and intervening skin), and generating both an innocuous pressure stimulus (35 gm) and a noxious pinch $(150 \mathrm{gm})$ with calibrated pinchers that had a contact area of $18 \mathrm{~mm}^{2}$. Both low- and high-intensity stimuli were applied to the contralateral hindpaw, as well. Only if the intracellular recording re- 
mained stable for the 12-15 min necessary to carry out this initial analysis of the receptive field twice was mustard oil applied to the skin.

The division of the receptive fields of the intracellularly recorded neurons into firing zones and into LPFFs was performed using the following criterion for a firing zone: "those skin areas where the mean number of spikes, in 50 msec periods over the course of a stimulus, exceeded the mean plus one standard deviation of the spontaneous discharge calculated for 50-msec intervals over a similar time period" (Woolf and King, 1989). If a response was less than this value, then the criterion used to decide whether the stimulus lay within a LPFF or outside the detectable mechanoreceptive field was whether the stimulus produced a subthreshold depolarization qualitatively different from spontaneous EPSPs (Woolf and King, 1989).

Mustard oil (allyl isothiocyanate, $5 \%$ in mineral oil) was painted onto a small $\left(4 \mathrm{~mm}^{2}\right)$ patch of hairy skin close to, but not overlapping with, the firing zone of the receptive field. This method of application has been shown by single fiber recording (Woolf and Wall, 1986) to produce a focal area of $\mathrm{C}$-afferent fiber activation.

Laminar locations of the recording sites were estimated from measurements of the depth of the electrodes from the surface of the cord. While this method is sufficiently accurate to differentiate neurons located in the superficial laminae of the dorsal horn from those in the deep laminae (Woolf and King, 1987, 1989), it cannot definitively identify the particular lamina in which a given neuron is located.

\section{Results}

The effect of the application of mustard oil to the skin on the cutaneous mechanoreceptive fields of 32 lumbar dorsal horn neurons has been studied in 32 decerebrate, spinal rats. Twentysix of the cells were recorded extracellularly and 6 intracellularly. The recording sites of 8 cells were estimated to lie within the superficial laminae of the dorsal horn (laminae 1 and 2) and 24 in the deep dorsal horn (laminae 4-6).

\section{Pre-mustard oil control data}

All the cells had cutaneous mechanoreceptive fields on the ipsilateral hindlimb. Differences in mechanosensitivity of the receptive fields enabled the cells to be classified as being either nociceptive specific, responding only to intense mechanical (pinch) stimuli $(n=8)$, low threshold only, responding maximally to low-intensity brush or touch stimuli, $(n=6)$, or multiconvergent, responding both to low-and high-intensity stimuli $(n=18)$. Table 1 indicates the distribution of the recording sites of the different classes of cells.

The mean membrane potential of the 6 intracellularly recorded cells was $-57 \mathrm{mV}(\mathrm{SE}, \pm 0.9 \mathrm{mV})$. The receptive fields of these cells could be divided into firing zones, where mechanical stimulation of the skin generated an action potential discharge above the background activity, and into LPFFs (Woolf and King, 1989), where EPSPs were elicited by a cutaneous stimulus, but the spike discharge fell within the range of background activity. Firing zones were present in all 6 of these cells and LPFFs were detected in 5. Defined in terms of their action potential discharges to graded mechanical stimulation in the firing zones, 5 of the cells were multireceptive and 1 nociceptive specific. The response to a pinch stimulus in the LPFF typically consisted of a train of high-frequency, small amplitude subthreshold EPSPs superimposed upon a sustained depolarization (5$15 \mathrm{mV}$; Fig. 2). A touch or brush stimulus in the fringe produced composite EPSPs of variable amplitude and duration that tended, in some cases, to entrain the ongoing action potential discharge with the stimulus (Fig. 3). The relative distribution of the firing zones and the LPFFs of 4 cells are shown in Figures 2 and 3 . Differences in the action potential response evoked by stimuli applied in the firing zone and the LPFF are illustrated in the ratemeter recordings in Figures 4 and 5.
Table 1. Properties of cells with recording sites in the superficial and deep laminae of the dorsal horn, and the changes produced by the cutaneous application of mustard oil

\begin{tabular}{lll} 
Cells recorded & $\begin{array}{l}\text { Superficial } \\
\text { laminae }\end{array}$ & $\begin{array}{l}\text { Deep } \\
\text { laminae }\end{array}$ \\
\hline Nociceptive-specific & 8 & 24 \\
Low-threshold-only & 5 & 3 \\
Multiconvergent & 0 & 6 \\
Direct activation by mustard oil & 3 & 15 \\
Receptive field expansion & 5 & 12 \\
Increased responsiveness & 4 & 17 \\
\hline
\end{tabular}

The number of spikes generated by stimulating the center of the firing zones of the receptive fields of both the extra- and intracellularly recorded neurons with a standard low- and highintensity mechanical stimulus varied by less than $25 \%$ when tested on 5 separate occasions in 28 of the 32 cells. In the 4 cells where the variation was greater, it never exceeded $40 \%$. The boundaries of the firing zones of the receptive fields remained unchanged in all but 3 cells over the control period, and, in these 3 cells, only a maximal increase of $20 \%$ in the size of the zone occurred over the control period. The LPFFs remained stable throughout the control period in the 5 intracellularly recorded cells where they could be detected.

\section{Application of mustard oil}

Mustard oil elicited a discharge of action potentials in 17 of the 32 cells, indicating that these cells' chemosensitive firing zones were larger than their mechanosensitive ones (e.g., Fig. 1). The latency to the firing was $14 \pm 3.5 \mathrm{sec}$, SE and lasted for $185 \pm$ $35 \mathrm{sec}$. Table 1 shows the location of the mustard-oil-responsive neurons, and Table 2 indicates that, while the majority of cells with a high-threshold component to their receptive fields fired in response to the mustard oil, this was not true for neurons dominated by low-threshold inputs. Mustard oil produced a depolarization in 3 of the 6 intracellularly recorded cells, which returned to control levels within $6 \mathrm{~min}$ (Fig. 6). The input resistance of 4 cells tested for $5 \mathrm{~min}$ before and after the mustard oil application was found not to change (mean value, $22.9 \pm$ 4.8 $\mathrm{M} \Omega$ ).

Following the mustard oil application, a marked expansion (greater than $25 \%$ ) in the size of the firing zone of the cutaneous receptive fields occurred in 17 cells (13 extracellular and 4 intracellular; see Figs. 1-3). The mean increase in size of the firing zone was $76 \pm 26 \%$. In 4 cells, the mustard oil produced a small expansion (15-25\%) and in 9, no change in the size of the firing

Table 2. The response of different classes of dorsal horn neurons to the cutaneous application of mustard oil

\begin{tabular}{llll} 
Cells recorded & $\begin{array}{l}\text { Nocicep- } \\
\text { tive- } \\
\text { specific }\end{array}$ & $\begin{array}{l}\text { Low- } \\
\text { thres- } \\
\text { hold-only- }\end{array}$ & $\begin{array}{l}\text { Multi- } \\
\text { con- } \\
\text { vergent }\end{array}$ \\
\hline Direct activation by mustard oil & 8 & 6 & 18 \\
Receptive field expansion & 5 & 1 & 11 \\
Increased responsiveness & 6 & 0 & 11 \\
& 7 & 2 & 14
\end{tabular}




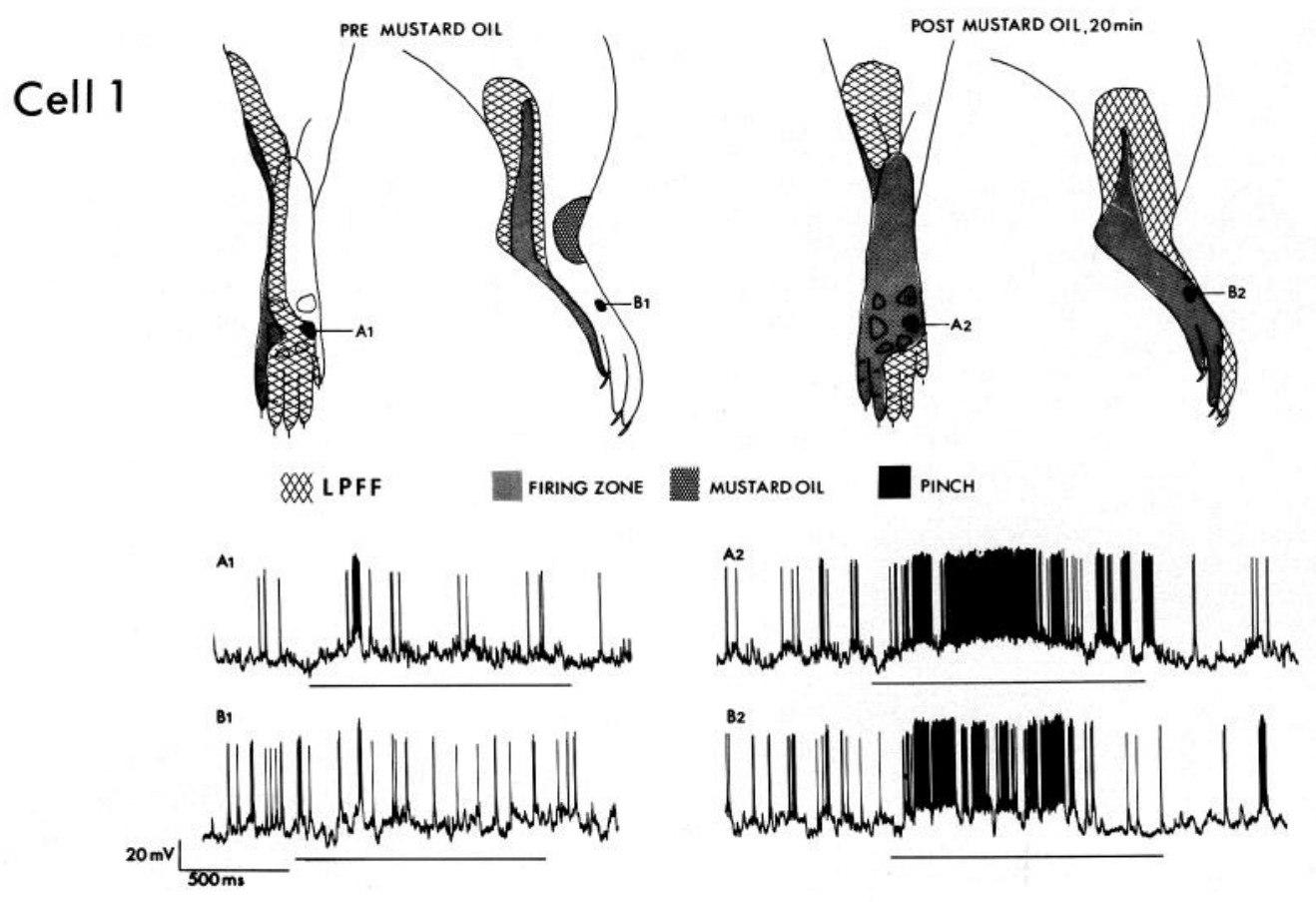

Figure 2. Changes in the size and re-
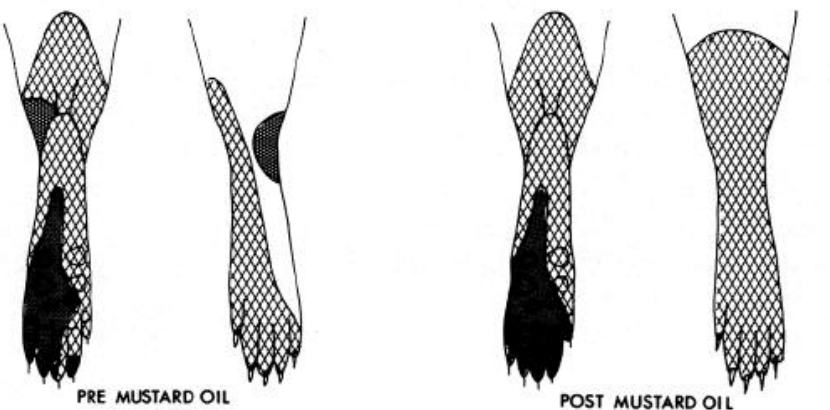

LPFF

Cell 2

sponsiveness of high threshold (pinch)

cutaneous receptive fields of 2 dorsal horn neurons following the application of mustard oil to the skin. For each cell, the change in the size of both the firing zone and the LPFF at $20 \mathrm{~min}(\mathrm{Cell} \mathrm{I})$ and $15 \mathrm{~min}$ (Cell 2) after the mustard oil is illustrated. Intracellular records of the alterations of responses are shown: for Cell 1, standard pinch $(150 \mathrm{gm})$ to 2 skin areas (A1 in the LPFF, B1 outside this fringe) 20 min after mustard oil; for Cell 2, standard pinch to toe 2 at 5 and 10 min after mustard oil.

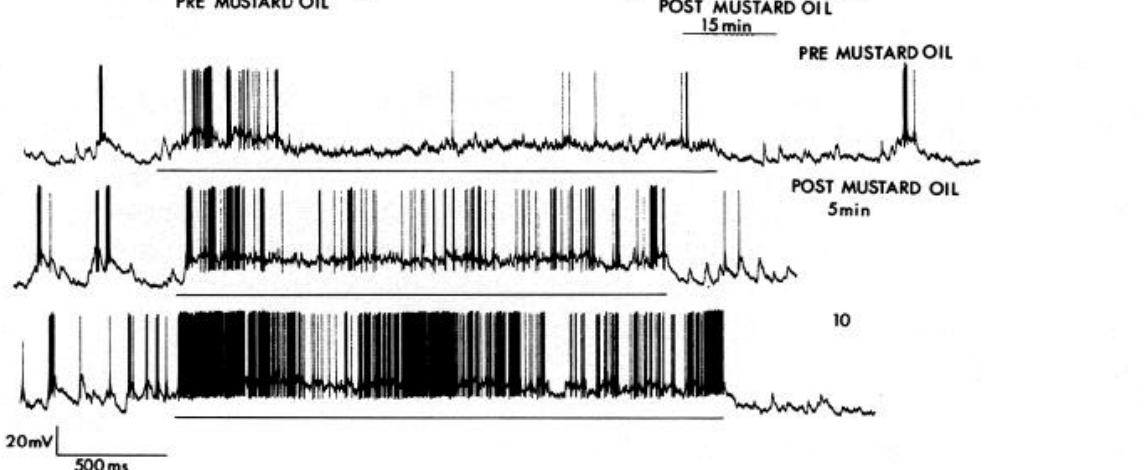

zone. An expansion of inhibitory receptive fields occurred in 2 cells after the mustard oil, and a novel contralateral firing zone appeared in 3 cells. The number of cells recorded in different laminae and responding to different stimulus modalities that exhibited changes in firing zones is given in Tables 1 and 2.
Cells with low-threshold-only receptive fields failed to show an expansion, although the low-threshold components of the receptive fields of multiconvergent cells did increase in size (Figs. $1,3)$. Not all cells that fired in response to the application of mustard oil showed receptive field expansion, and the reverse 
Cell 1

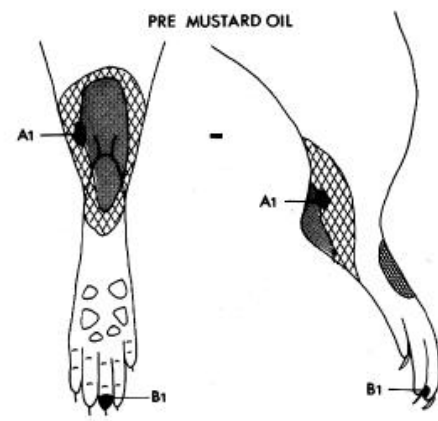

LPFF

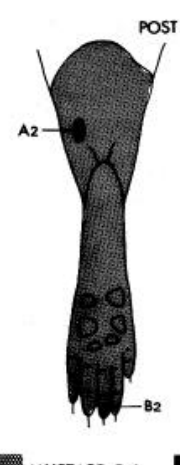

MUSTARD OIL

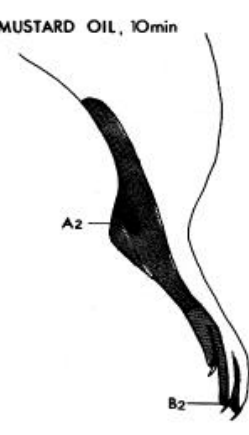

LIGHT TOUCH/BRUSH
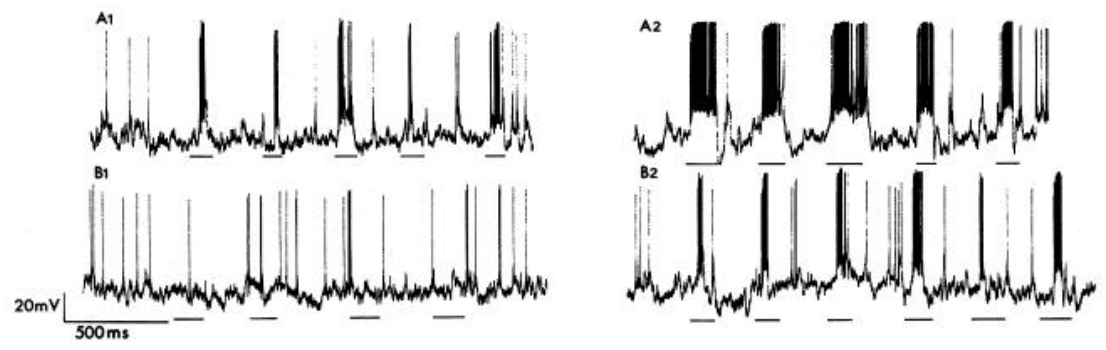

Cell 2

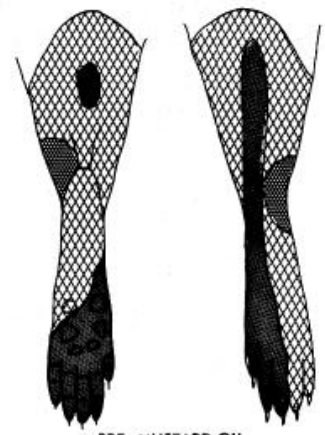

PRE MUSTARD OIL

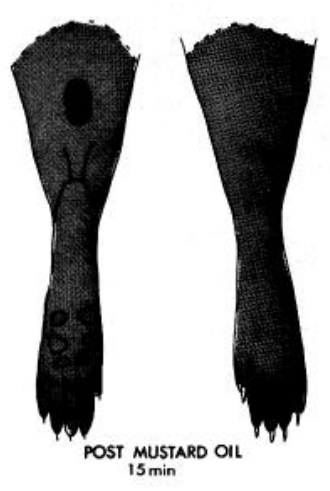

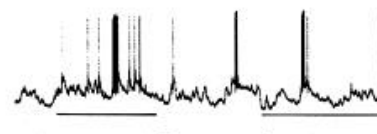
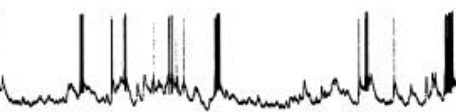
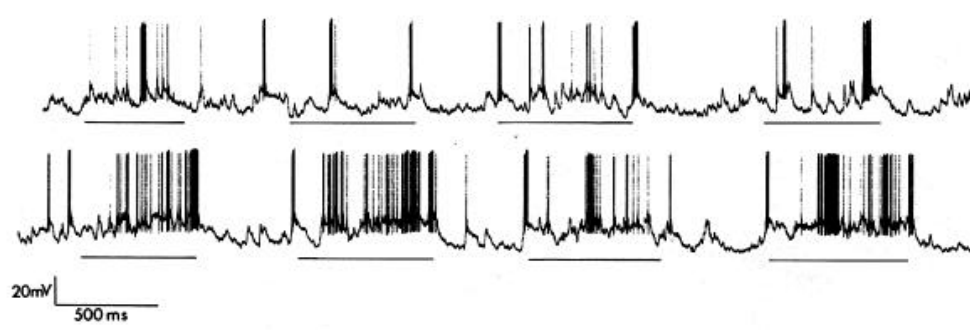

PRE MUSTARD OIL

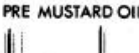

(ing

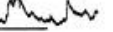

LPFF

FIRING ZONE

MUSTARD OIL

BRUSH

Figure 3. Changes in the low threshold (brush and touch) cutaneous receptive fields of 2 dorsal horn neurons following the cutaneous application of mustard oil. For each cell, the change in the size of both the firing zone and the LPFF at $10 \mathrm{~min}$ (Cell $\mathrm{l}$ ) and $15 \mathrm{~min}$ (Cell 2) after the mustard oil is illustrated. Intracellular records of the alterations of responses are shown: for Cell 1, brushing 2 skin areas (A1 at the border between the LPFF and the firing fringe, $\mathrm{B} 1$ outside the fringe) $10 \mathrm{~min}$ after mustard oil; for Cell 2, brushing an area of skin in the LPFF 10 min after mustard oil. was also true: only 12 of the 17 cells that expanded their receptive fields were directly activated by the mustard oil. Because spontaneous subthreshold activity increased in all cells after the mustard oil application, it was difficult to accurately map the outer limits of the LPFF in the intracellularly recorded neurons, but, in 4 cells, the fringe could be seen to increase in size (Figs.
2, 3). Expansion began within 5-20 min of application of the mustard oil $(8 \pm 1.4 \mathrm{~min})$, peaked at $26 \pm 3.7 \mathrm{~min}$, and, in 5 cells, returned to control levels between 30 and $105 \min (68 \pm$ $7 \mathrm{~min}$ ). In the other 12 cells, expansion was still present when recordings from the cells were lost at between 22 and $90 \mathrm{~min}$. No correlation could be made between the extent of the expan- 


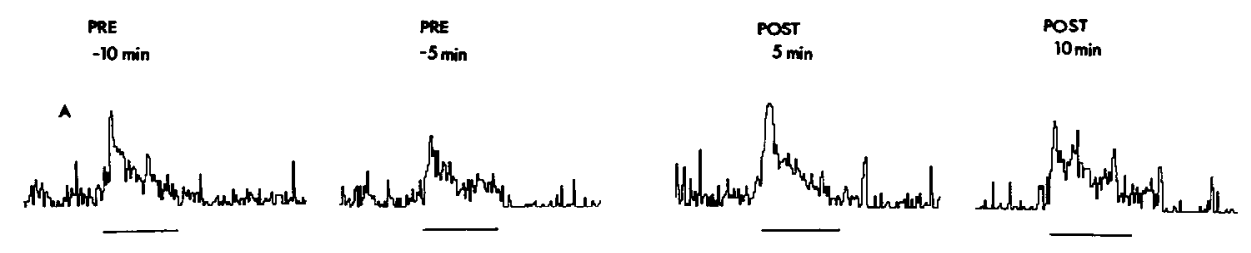

Figure 4. Ratemeter recordings of spike discharge elicited from intracellularly recorded dorsal horn neuron by stimulating 4 different skin areas $(A-D)$ with a pinch $(A, C)$ or brush $(B, D)$ stimulus before (PRE) and after (POST) the application of mustard oil to the skin. $A$ and $B$ were within the firing zone of the cell, and $C$ and $D$ were in the LPFF. The timing of the stimuli is indicated by the lines under the traces. Note the increased discharge evoked by stimuli in the firing zone after mustard oil $(A$, $B)$ and the recruitment of a novel action discharge to brush stimuli $(D)$ but not but not to pinch $(C)$. Bin width, $50 \mathrm{msec}$.
B

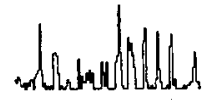

c
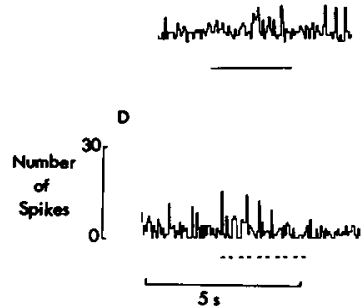
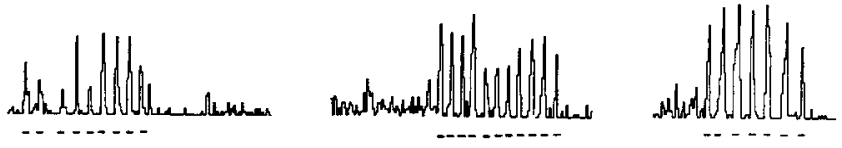
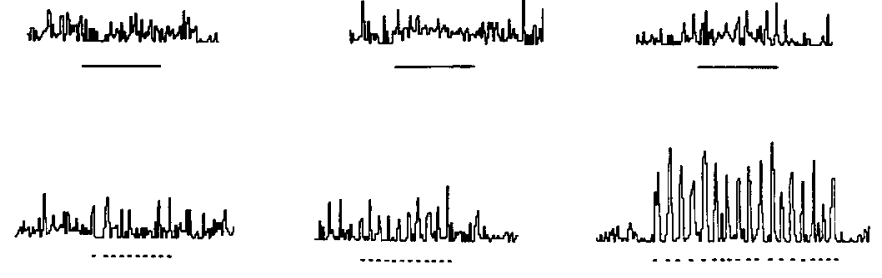

sion produced by the application of the mustard oil and either the degree of the depolarization or the action potential discharge that it produced (Fig. 6).

Mustard oil application also altered the responses generated by standard stimuli applied to the original firing zones of the receptive fields in 23 of the 32 cells. In 20 cells, this manifested as an increase in responsiveness, including the novel appearance of afterdischarges (Figs. 4, 5). Three cells showed potentiated inhibitory responses in one part of the receptive field and a potentiated excitatory response in another. Increases in both the peak frequency (range, 16-189\%) and in the total number of spikes elicited (range, 24-372\%) by both low- and high-intensity stimuli occurred. The ratemeter records in Figures 4 and 5 show examples of changes in responsiveness in both the firing zone (Figs. $4, A, B ; 5$, stimuli 5, 6, 7) and the novel recruitment of an action potential discharge from what originally had been an LPFF (Figs. 4D; 5, stimuli 8, 9). Although increases in responsiveness were found in all classes of cells (Table 2), such changes were more frequent in cells with a high threshold input. In 8 cells, a change in responsiveness was examined by comparing the response elicited by a brief train of electrical stimuli through pin electrodes applied to the firing zone $(400 \mu \mathrm{A}, 500 \mu \mathrm{sec}$ at 1 $\mathrm{Hz}$ for $5 \mathrm{sec}$ ) before and after the mustard oil. In those 5 cells where the response to a natural stimulus increased, the response to the electrical stimuli also increased.

Changes in responsiveness in the intracellularly recorded cells were associated with larger depolarizations in response to the standard stimuli (Figs. 2, 3, 7). Brush-evoked depolarizations in the firing zone prior to the application of the mustard oil had a mean value of $16.1 \pm 3.6 \mathrm{mV}$ that increased to $21.7 \mathrm{mV}$ (SD, $\pm 3.9 \mathrm{mV} ; n=6 ; p<0.05$ ) after the mustard oil. The mean control depolarization in response to pinch was $15.3 \pm 4.1 \mathrm{mV}$, which increased after the application of the mustard oil to 23.5 $\pm 4.2 \mathrm{mV}(n=6, p<0.01)$. The extent of the depolarization after mustard oil application was ultimately sufficient to produce an inactivation of the action potentials in 2 cells (Fig. 7). The expansion of the firing zone into an area previously LPFF was also associated with an increase in the amplitude of the depolarization produced. The standard pinch stimulus applied to an area of skin in the LPFF during the control period produced a depolarization of $10.5 \pm 2.4 \mathrm{mV}$. This increased to $17.4 \pm 4.5$ $\mathrm{mV}(n=5)$ after the mustard oil. Although the increased responsiveness and the expansion occurred together in 15 cells, 2 expanded without an increase in responsiveness, and 9 increased their responsiveness without an expansion. The time course of the expansion and the altered responsivenenss were nevertheless very similar.

The 8 nociceptive-specific cells had mechanical thresholds of $55 \pm 8$ gm prior to the mustard oil. In 4 , the threshold dropped to $6.9 \pm 2 \mathrm{gm}$ after the mustard oil. This drop in threshold was accompanied by the appearance of a novel brush, touch, or pressure component to the firing zone, which, in the case of 1 intracellularly recorded cell, had been subthreshold before the mustard oil treatment.

\section{Discussion}

The cutaneous receptive field properties of dorsal horn neurons derive from the anatomical arrangements of the central terminals of functionally specialized primary afferent neurons, the dendritic distribution and intrinsic membrane properties of dorsal horn neurons, and the patterns and strengths of the synaptic connections between the primary afferents and the dorsal horn neurons and between the spinal neurons themselves. These receptive fields reflect, in a modified way, the patterns of input generated by stimulation of the skin. While the anatomical constraints of the system are fixed under normal circumstances, this does not necessarily imply that the spatial extent or pattern of responsiveness of the receptive field of a given dorsal horn neuron is also fixed. On the contrary, the results of this study and others show that the receptive fields can be modified shortly after the occurrence of certain afferent inputs. In order to understand the mechanisms contributing to this dynamic receptive field plasticity, we need to appreciate both which elements of the system are changeable and what triggers such changes. 
Pre MO 5 min Post MO $10 \mathrm{~min}$ Post $\mathrm{MO}$

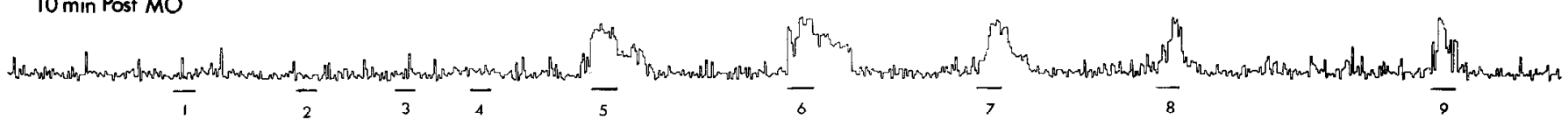
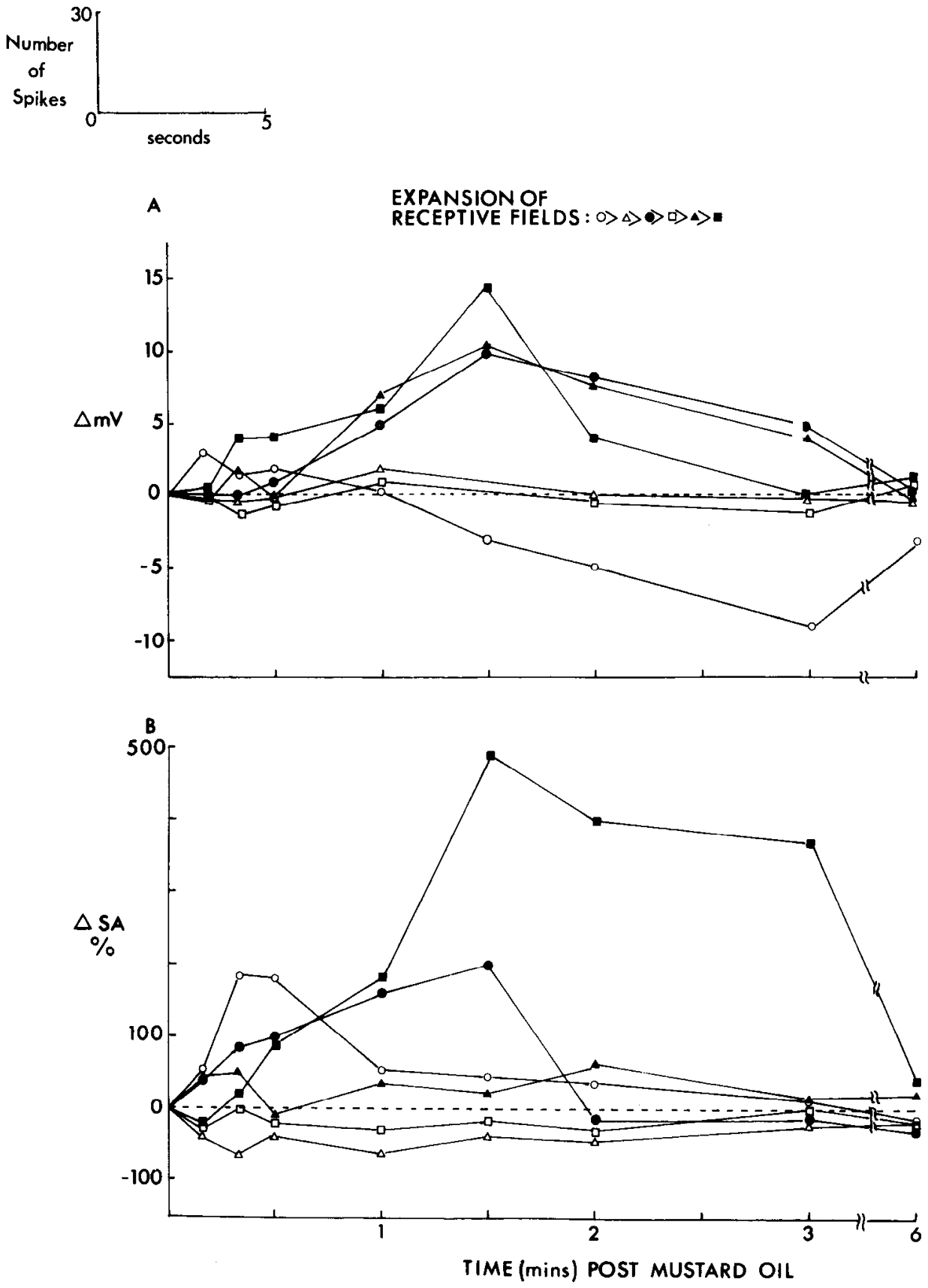

Figure 5. A ratemeter record of the action potential discharge of an intracellularly recorded dorsal horn neuron to a sequence of brief pinch stimuli applied to the skin before and after application of mustard oil. Stimuli $1,2,3$, and 4 elicited no detectable response and were considered to be applied to an area outside the receptive field. Stimuli 5, 6, and 7 produced a discharge of action potentials above the background and were therefore within the firing zone. Stimuli 8 and 9 in the control period elicited a distinct depolarization, but the discharge of action potentials could not be differentiated from the background and therefore lay within the LPFF. Following the mustard oil, there are increases in the responses to stimuli 5 , 6 , and 7 and the appearance of a novel action potential discharge to stimuli 8 and 9 . Bin width, $50 \mathrm{msec}$.
Figure 6. $A$, The changes in membrane potential in 6 dorsal horn neurons produced by the application of mustard oil to the skin. $B$, The alteration in the background or spontaneous activity (SA) produced following the mustard oil. The key at the top of the figure illustrates the relative expansions of the firing zones of the different cells. 


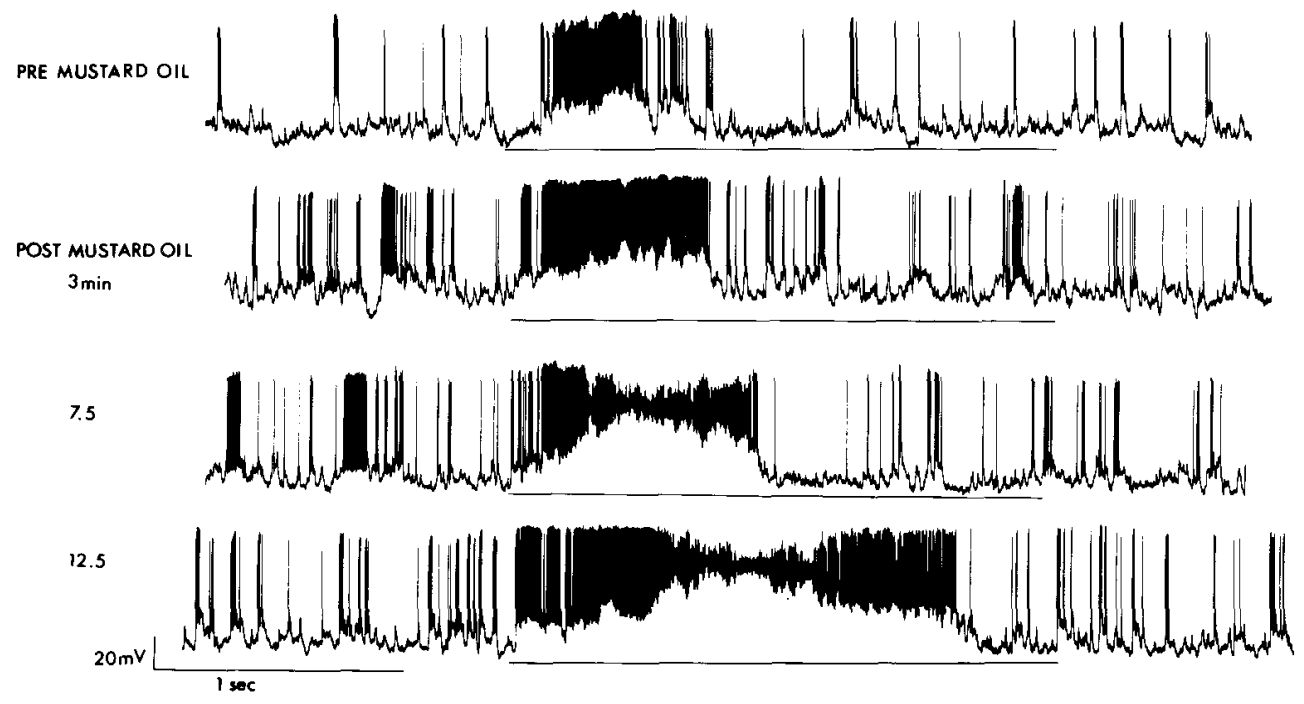

Figure 7. The effect of a standard pinch (150 gm) applied to the firing zone of a dorsal horn before and at various times after the cutaneous application of mustard oil, showing the increase in the depolarization elicited, which eventually resulted in spike inactivation.

The 2 potentially variable elements that could contribute to alterations in receptive field properties are synaptic efficacy and membrane excitability. Multiple pre- and postsynaptic mechanisms could operate to increase or decrease the effectiveness of an afferent input in a use-dependant or independent way (Mendell, 1984). These would include alterations in pre- or postsynaptic inhibition; transmitter release, uptake, or breakdown; postsynaptic receptor activation; and ligand- or voltagegated channel opening or closing. The NMDA excitatory amino acid receptor's voltage-dependent $\mathrm{Mg}^{2+}$ block (Mayer et al., 1984 ) is one example of how an activity-dependent change could operate postsynaptically. Modifications in intrinsic membrane properties triggered by an afferent input could be due to the inhibition of persistent outward currents such as the M-current (Adams and Brown, 1982), the activation of calcium inward currents (Murase et al., 1986), or changes in dendritic currents (Jahnsen and Llinas, 1984).

The potential importance of changes in synaptic or membrane function lies in the large subthreshold component of the receptive fields of dorsal horn neurons, both within the firing zone and surrounding it (Brown and Fyffe, 1981; Woolf and King, 1989). The size of the firing zone of the receptive field of a neuron can be augmented by recruiting the subliminal zone by depolarizing the cell (Brown and Fyffe, 1981). Similar changes follow the depolarization produced by the ionophoresis of glutamate (Zieglgansberger and Puil, 1973). The arrangement of the receptive fields of dorsal horn neurons appears, with intracellular analysis, not to be one of fixed inputs producing fixed responses, but rather one of a zone of focussed synaptic inputs surrounded by fringes of weaker inputs (Brown et al., 1987; Woolf and King, 1989). This means that the responsiveness of a cell, both in spatial terms and in terms of the pattern and amplitude of discharge evoked, has the potential to change, as we have demonstrated here. The changes we found following the application of mustard oil reflect, to a degree, the recruitment of previously subthreshold inputs, so that parts or all of the LPFF became incorporated into the firing zone, and subthreshold components of the firing zone became suprathreshold. However, because we were observing changes that occurred across a population of neurons, these changes are likely to differ from thuse that may be produced by depolarizing a single cell. If an excitatory interneuron feeding onto a cell that is being recorded expands its receptive field, it will alter the receptive field of the recorded cell in a way that could not be predicted from an analysis of the recorded cells' LPFF alone. Similarly, expansion of the receptive fields of inhibitory interneurons will alter the receptive fields of the neurons they contact in a complex fashion.

At present, we know little about the actual mechanisms involved in changing the receptive fields of dorsal horn neurons, although it does appear that these changes are related to the postsynaptic cell type. Cells with low-threshold-only receptive fields showed minimal expansion, but the low-threshold fields of multiconvergent cells changed. This may reflect differences in the direct or indirect inputs of chemosensitive $\mathrm{C}$-afferents to different classes of cells. That certain classes of noxious peripheral stimuli and the afferent barrage they initiate can induce changes in the properties of dorsal horn neurons is well documented. Chemical irritants such as mustard oil, capsaicin, or bradykinin are particularly effective (Simone et al., 1988; Hoheisel and Mense, 1989), although noxious pinch (Cervero et al., 1988) local inflammation (Hylden et al., 1989), and thermal stimuli (McMahon and Wall, 1984) also have been shown to alter the receptive fields of spinal and thalamic (Guilbaud et al., 1987) neurons. Electrical stimulation also produces these changes, provided the small-diameter afferents are activated (Cervero et al., 1984; Wall and Woolf, 1984; Cook et al., 1987).

Small-diameter primary afferents, in contrast to the large myelinated fibers, have the capacity to produce slow synaptic potentials in spinal neurons (Urban and Randic, 1984; King et al., 1989; Yoshimura and Jessell, 1989; Thompson et al., 1990). These slow potentials can summate to produce large depolarizations that outlast the stimulus for several minutes (Thompson et al., 1990) and, in this way, could recruit subliminal input to a suprathreshold level for a short period. These relatively shortlived changes cannot alone explain prolonged receptive field alterations. What may be occurring is that the neurotransmitters/neuromodulators that are responsible for producing slow potentials, substance P (Murase and Randic, 1984), calcitonin gene-related peptide (Ryu et al., 1988), or the activation of NMDA acid receptors (King et al., 1990; Thompson et al., 1990) may trigger longer lasting changes by activating second messenger systems that could produce a sustained change in membrane properties by phosphorylating membrane proteins. Af- 
ferent inputs and transmitters have been shown to alter calcium levels (Womak et al., 1988), protein kinase activity (Woolf, 1987), and the expression of the C-fos proto-oncogene (Hunt et al., 1987) in dorsal horn neurons.

Primary afferent-induced alterations in the receptive fields of dorsal horn neurons have implications for the pathogenesis of post-injury pain hypersensitivity phenomena. A feature of such hypersensitivity states is a reduction in the stimuli threshold necessary for the production of pain and a spread of sensitivity beyond the site of injury (Campbell et al., 1979; LaMotte et al., 1983; Raja et al., 1984). Sensitization of high-threshold primary afferent nociceptors contributes to the changes that occur, but central alterations are likely to be important as well (Woolf, 1983; Raja et al., 1988; Woolf, 1989). Increases in the size of the cutaneous receptive fields of dorsal horn neurons, the recruitment of novel low-threshold inputs, and an amplification of existing inputs as a consequence of a change in the excitability of dorsal horn neurons could all play a substantial role in the generation of the sensory disorders. By analogy with peripheral sensitization, the primary afferent input triggered by tissue-damaging stimuli may be considered to produce a state of central sensitization manifesting in the dorsal horn as a change in receptive field properties.

\section{References}

Adams PR, Brown DA (1982) Synaptic inhibition of the M-current: slow excitatory post synaptic potential mechanism in bullfrog sympathetic neurones. J Physiol (Lond) 332:263-279.

Brown AG, Fyffe REW (1981) Form and function of dorsal horn neurones with axons ascending the dorsal columns in the cat. J Physiol (Lond) 321:31-47.

Brown AG, Brown PB, Fyffe REW, Pubols LM (1983) Receptive field organization and response properties of spinal neurones with axons ascending the dorsal columns in the cat. J Physiol (Lond) 337:575588.

Brown AG, Koerber HR, Noble R (1987) An intracellular study of spinocervical tract cell responses to natural stimuli and single hair afferrent fibres in cats. J Physiol (Lond) 382:331-354.

Campbell JN, Meyer RA, LaMotte RH (1979) Sensitization of myelinated nociceptive afferents that innervate monkey hand. J Neurophysiol 42:1669-1679.

Cervero F, Shouenberg J, Sjolund BH, Waddell PJ (1984) Cutaneous inputs on dorsal horn neurones in adult rats treated at birth with capsaicin. Brain Res 300:47-57.

Cervero F, Handwerker HO, Laird JMA (1988) Prolonged noxious stimulation of the rats tail: responses and encoding properties of dorsal horn neurons. J Physiol (Lond) 404:419-436.

Cook AJ, WoolfCJ, Wall PD, McMahon SB (1987) Dynamic receptive field plasticity in rat spinal dorsal horn following C-primary afferent input. Nature 325:151-153.

Devor M, Wall PD (1981) Plasticity in the spinal cord sensory map following peripheral nerve injury in rats. J Neurosci 1:277-291.

Dubuisson D, Fitzgerald M, Wall PD (1979) Ameboid receptive fields of cells in laminae 1, 2, and 3. Brain Res 177:376-378.

Ferrington DG, Sorkin LS, Willis WD (1987) Responses of spinothalamic tract cells in the superficial dorsal horn of the primate lumbar spinal cord. J Physiol (Lond) 388:681-703.

Guilbaud G, Benoist JM, Neil A, Kayser V, Gautron M (1987) Neuronal response thresholds to and encoding of thermal stimuli during carrageenin-hyperalgesic inflammation in the ventrobasal thalamus of the rat. Exp Brain Res 66:421-431.

Hentall I (1977) A novel class of unit in the substantia gelatinosa of the spinal cat. Exp Neurol 57:792-806.

Hoheisel U, Mense S (1989) Long-term changes in discharge behaviour of cat dorsal horn neurones following noxious stimulation of deep tissues. Pain 36:239-247.

Hongo T, Koike H (1975) Some aspects of synaptic organization in the spinocervical tract. In: The somatosensory system (Kornhuber HH, ed), pp 218-226. Stuttgart: Thieme.
Hunt SP, Pini A, Evan G (1987) Induction of C-fos-like protein in spinal cord neurones following sensory stimulation. Nature 328:632634.

Hylden JLK, Nahin RL, Dubner R (1987) Altered responses of nociceptive cat lamina I dorsal horn neurons after chronic sciatic neuronal formation. Brain Res 411:341-350.

Hylden JLK, Nahin RL, Traub RJ, Dubner R (1989) Expansion of receptive fields of spinal lamina $I$ projection neurons in rats with unilateral adjuvant-induced inflammation: the contribution of dorsal horn mechanisms. Pain 37:229-243.

Jahnsen H, Llinas R (1984) Electrophysiological properties of Guineapig thalamic neurons: an in vitro study. J Physiol (Lond) 349:205226.

King A. Thompson SWN, WoolfCJ (1989) Activation of ventral horn neurones by peripheral nerve and skin stimulation in the rat isolated spinal cord-hindlimb preparation. J Physiol (Lond) 412:25P.

King A, Thompson SWN, Woolf CJ (1990) Prolonged postsynaptic depolarizations evoked in ventral-horn neurones following stimulation of small calibre primary afferents in the isolated rat hemisected spinal cord/hindlimb preparation are APV-sensitive. J Physiol (Lond) 422: $7 \mathrm{p}$.

LaMotte RH, Thalhammer JG, Robinson CJ (1983) Peripheral neural correlates of magnitude of cutaneous pain and hyperalgesia: a comparison of neural events in monkey with sensory judgements in human. J Neurophysiol 50:1-26.

Markus H, Pomeranz B (1987) Saphenous has weak ineffective synapses in sciatic territory of rat spinal cord: electrical stimulation of the saphenous or application of drugs reveal these somatotopically inappropriate synapses. Brain Res 416:315-321.

Mayer ML, Westbrook G, Land Guthrie PB (1984) Voltage-dependent block by $\mathrm{Mg}^{2+}$ of NMDA responses in spinal cord neurones. Nature 309:261-263.

McMahon PD, Wall PD (1984) Receptive fields of rat lamina I projection cells move to incorporate a nearby region of injury. Pain 19: 235-247.

Mendell LM (1984) Modifiability of spinal synapses. Physiol Rev 64: 260-324.

Murase K, Randic M (1984) Actions of substance P on rat spinal dorsal horn neurones. J Physiol (Lond) 346:203-217.

Murase K, Ryu PD, Randic M (1986) Substance P augments a persistent slow inward calcium sensitive current in voltage clamped spinal dorsal horn neurones of the rat. Brain Res 265:369-376.

Raja S, Campbell JN, Meyer RA (1984) Evidence for different mechanisms of primary and secondary hyperalgesia following heat injury to the glabrous skin. Brain 107:1179-1188.

Raja S, Campbell JN, Meyer RA (1988) Peripheral mechanisms of somatic pain. Anesthesiol 68:571-590.

Ryu PD, Gerber G, Murase K, Randic M (1988) Actions of calcitonin gene-related peptide on rat spinal dorsal horn neurons. Brain Res 441: 357-361.

Schaible HG, Schmidt RF, Willis WD (1987) Enhancement of the responses of ascending tract cells in the cat spinal cord by acute inflammation of the knee joint. Exptl Brain Res 66:489-499.

Simone DA, Sorkin LS, Chung IM, Willis WD, LaMotte RH (1988) Spinothalamic tract cells signal the pain and hyperalgesia following intradermal capscaicin. Soc Neurosci Abstr 14:559.

Thompson SWN, King AE, Woolf CJ (1990) Activity-dependent changes in rat ventral horn neurons in vitro: summation of prolonged afferent evoked postsynaptic depolarizations produce a D-2-aminophosphorovaleric acid sensitive windup. Eur J Neurosci (in press).

Urban L, Randic M (1984) Slow excitatory transmission in rat dorsal horn: possible mediation by peptides. Brain Res 290:336-341.

Wall PD (1977) The presence of relatively ineffective synapses and circumstances that unmask them. Phil Trans R Soc Lond [Biol] 278: 361-372.

Wall PD, Woolf CJ (1984) Muscle but not cutaneous C-afferent input produced prolonged increases in the excitability of the flexion reflex in the rat. J Physiol (I ond) 356:443-458.

Womack MD, MacDermott AB, Jessell TM (1988) Sensory transmitters regulate intracellular calcium in dorsal horn neurones. Nature $334: 351-353$.

Woolf CJ (1983) Evidence for a central component of postinjury pain hypersensitivity. Nature 308:686-688.

WoolfCJ (1984) Long term al terations in the excitability of the flexion reflex produced by peripheral tissue injury in the chronic decerebrate rat. Pain 18:325-343. 
Woolf CJ (1987) Excitatory amino acids increase glycogen phosphorylase activity in the rat spinal cord. Neuroscience Lett 73:209-214.

Woolf CJ (1989) Recent advances in the pathophysiology of acute pain. Br J Anaesth 63:139-146.

Woolf CJ, Fitzgerald M (1983) The properties of neurons recorded in the superficial dorsal horn of the rat spinal cord. J Comp Neurol 221: 313-328.

Woolf CJ, King AE (1987) Physiology and morphology of multireceptive neurons with $\mathrm{C}$-afferent fibre inputs in the deep dorsal horn of the rat lumbar spinal cord. J Neurophysiol 58:105-119.

Woolf CJ, King AE (1988) Subliminal fringes and the plasticity of dorsal horn neuron's receptive field properties. Soc Neurosci Abstr 14:696.
Woolf CJ, King AE (1989) Subthreshold components of the receptive fields of dorsal horn neurones in the rat. J Neurophysiol 62:907-916.

Woolf CJ, McMahon SB (1985) Injury-induced plasticity of the flexor reflex in chronic decerebrate rats. Neuroscience 16:395-404.

Woolf CJ, Wall PD (1986) The relative effectiveness of C primary afferent fibres of different origins in evoking a prolonged facilitation of the flexor reflex in the rat. J Neurosci 6:1433-1443.

Yoshimura M, Jessell TM (1989) Primary afferent evoked synaptic responses and slow potential generation in rat substantia gelatinosa neurons in vitro. J Neurophysiol 62:96-108.

Zieglgansberger W, Puil EA (1973) Actions of glutamic acid on spinal neurones. Exptl Brain Res 17:35-49. 